Western University Scholarship@Western

Law Publications

Law School

1996

\title{
Control of Community Information: An Analysis of Roles
}

Margaret Ann Wilkinson

Western University, mawilk@uwo.ca

Karen Pettigrew

Follow this and additional works at: https://ir.lib.uwo.ca/lawpub

Part of the Law Commons

Citation of this paper:

Wilkinson, Margaret Ann and Pettigrew, Karen, "Control of Community Information: An Analysis of Roles" (1996). Law Publications.

67.

https://ir.lib.uwo.ca/lawpub/67 
Control of Community Information: An Analysis of Roles

Author(s): Karen E. Pettigrew and Margaret Ann Wilkinson

Source: The Library Quarterly: Information, Community, Policy, Vol. 66, No. 4 (Oct., 1996), pp. 373-407

Published by: The University of Chicago Press

Stable URL: http://www.jstor.org/stable/4309155

Accessed: 03-06-2015 16:04 UTC

Your use of the JSTOR archive indicates your acceptance of the Terms \& Conditions of Use, available at http://www.jstor.org/page/ info/about/policies/terms.jsp

JSTOR is a not-for-profit service that helps scholars, researchers, and students discover, use, and build upon a wide range of content in a trusted digital archive. We use information technology and tools to increase productivity and facilitate new forms of scholarship. For more information about JSTOR, please contact support@jstor.org. 


\title{
CONTROL OF COMMUNITY INFORMATION: AN ANALYSIS OF ROLES ${ }^{1}$
}

\author{
Karen E. Pettigrew² and Margaret Ann Wilkinson ${ }^{3}$
}

Many formal and informal sources within a community disseminate community information. People seek information from their peer-kin network, directly from service providers, and from intermediaries, such as libraries and information and referral (I\&R) agencies. I\&R agencies specialize in community information by maintaining an inventory of the area's human services and disseminating that information to the public. Another recently developed vehicle for this information is the online community network, an electronic environment where service providers can post information about their services and members of the public can then access that information using a computer and modem. But the respective roles of $I \& R$ agencies and community networks are unclear: are they, in part or in whole, providing the same service or product? What are the implications for funding and data collection if they are? If not, what relationship, if any, should they have with each other? This study explores the differences between I\&R agencies and community networks from an information policy perspective and uses a framework proposed by Wilkinson (1992) to analyze the positioning of control within the two intermediaries under six facets: agency ownership and governance, funding, information flow, access, information ownership, and quality control. Existing community networks and I\&R agencies are used as examples to illustrate the arguments.

Many sources within a community disseminate community information, both formally and informally. Individuals seek information from their peer-kin network, directly from service providers, such as the Ontario Ministry of Housing, and from intermediaries, such as libraries and infor-

1. We would like to thank Jean Tague-Sutcliffe, Dean, Graduate School of Library and Information Science, University of Western Ontario, and the anonymous referees for editorial comments on our manuscript.

2. Graduate School of Library and Information Science, University of Western Ontario, London, Ontario N6G 1H1, Canada; telephone: 519-679-2111, extension 8516; E-mail kpettigr@julian.uwo.ca.

3. Faculty of Law and Graduate School of Library and Information Science, University of Western Ontario.

[Library Quarterly, vol. 66, no. 4, pp. 373-407]

(C) 1996 by The University of Chicago. All rights reserved. 0024-2519/96/6604-0003\$01.00 
mation and referral (I\&R) agencies. I\&R agencies specialize in community information primarily by maintaining an inventory of their community's human services and disseminating that information to the public. Another recently developed vehicle for community information is the online community network, an electronic environment where service providers can post information about their services and members of the public can then access that information using a computer and modem. However, the explosion of community networks across North America may challenge the older facilitators, the $I \& R$ agencies, in three areas: (1) when they seek to attract funding from the same agencies, (2) when they seek to collect community information data from the same organizations and service providers, and (3) when they seek to meet the needs of the public they are intending to serve. Indeed, situations have already arisen where the need for I\&R agencies has been questioned upon the arrival of community networks. For example, Dick Manikowski [1] described a colleague's situation where potential funders balked at plans to automate an I\&R agency since that area already had a community network and the public library announced plans to upload a database of local human service providers. The funders' position, wrote Manikowski, was that "there will already be an electronic database of human services available to the community without any additional expense and that automating the [I\&R] agency's files would be wasteful" $[1, \mathrm{p} .10]$. Manikowski added that while it is possible that the funders used this argument as "an easy way to say no," it is also possible that "they're serious in confusing a publicly accessible database with the resource file which the I\&R agency maintains" [1, p. 10].

Both the American and Canadian governments have recognized the importance of delivering community information in tandem with our emerging information society $[2,3]$. Proponents of community networks see their electronic pathways as the logical vehicle for delivering community information (and other services) twenty-four hours a day into every home and shopping mall. As a result of financial constraints, most I\& $R$ agencies cannot provide such round-the-clock service. While neither the U.S. nor the Canadian government has a federal policy on the provision of $I \& R$, both governments have recognized the need to provide adequate access to quality information (that is, accurate, current, and comprehensive) as a means of empowering citizens so that they can participate democratically in their local and global communities $[3,4] .{ }^{4}$ How can efficiency and effectiveness in delivering community information be achieved?

4. In the United States, for example, Vice President Al Gore remarked on "bringing the Information Revolution to every classroom, hospital and library in the Nation by the end of the century" [4]. 


\section{Literature Review}

No research has been conducted to date on the control of community information in the sense that the concept is explained in this article. While there is a growing body of empirical research and theory on the information-seeking behavior of the public as reviewed by Roma Harris and Patricia Dewdney [5], little research has actually focused on community networks [6] or I\&R agencies. Aside from two recent master's theses by Andrew Avis [7] and Anne Beamish [8], most literature on existing community networks and services [9-15] is of an instructional and descriptive nature rather than analytical. Notwithstanding the research conducted by Thomas Childers [16] on I\&R services in public libraries, the literature on independent I\&R agencies has also tended to be of a descriptive or applied nature. To date, the most extensive index to the I\&R literature is an annotated bibliography compiled by Dick Manikowski and Norman Maas [17], while Risha Levinson's work [18] is highly recommended for a comprehensive review of the history and current operations of $I \& R$ agencies in North America and the United Kingdom. Margaret Ann Wilkinson [9] is one of a few researchers who have attempted to study empirically the control of information, although in a slightly different context, and her theoretical model provides the basis for this article.

\section{Research Objectives}

In seeking to explore the challenges facing both community networks and I\&R agencies, this study focuses on a search between the two from an information policy perspective. The study concentrates on the question of control for each of the two types of organizations, where control is defined as the power to direct, command, or dominate an activity or outcome. Whoever possesses control ultimately determines the shape and success of a service, and only once these sources of control have been identified can the implications of that control for service delivery of community information be discussed. Hence, for each of the two types of facilitators (I\&R agencies and community networks), the objective is to identify where control lies within the following facets: (1) agency ownership and governance, (2) funding, (3) information flow, (4) access, (5) ownership of information, and (6) quality control.

\section{Theoretical Framework and Methodology}

This investigation was conducted using an information policy framework adapted from Wilkinson's [19] work on the implementation of 
access to information and privacy legislation in provincial ministries and corporations in Ontario. The data used in our analysis consisted primarily of policy documents obtained from existing I\&R agencies and community networks and the associations to which they belong. Two organizations in particular were chosen for case study: Information London, an I\&R agency in London, Ontario, and the National Capital Freenet, a community network in Ottawa, Ontario. Each follows an internationally recognized model. Information London is a member of the Alliance of Information and Referral Systems (AIRS), while the National Capital Freenet follows the guidelines of the National Public Telecomputing Network. Their relationships with these organizations are described below. Before proceeding with our analysis of control within these environments, a number of key terms need to be clearly defined. These terms are considered as two conceptual groups: process definitions (information and community information) and the players (I\&R agencies, community networks, service providers, and users).

The question of the respective roles of the I\&R agency and the community network must be discussed within a context common to both agencies. The first task of this inquiry, therefore, is to establish that common context, if possible. Are the two agencies engaged in the same aspect of the information process? In order to discuss information processes, we require an understanding of information. Wilkinson has defined information as "all data which have been made to flow." ${ }^{15}$ From this definition, we can envisage three ways of defining community information: (1) all data (about a community) that have been made to flow, or (2) all original data that have been made to flow from within the community, or (3) all data that are flowing anywhere that is useful to a community. Of these possible definitions, the third is the most encompassing because the source of the information may be anywhere, while the information may be on any subject. The only criterion for inclusion is that the information be useful to someone in the community. It is indeed theoretically possible, but almost certainly empirically not the case, that every item of data in the world is wanted by someone in the community. (The proportions in fig. 2 do not claim to be accurate: the diagram merely illustrates relationships.) The second is narrower because it restricts the sources of the information to those within the community, although the subject matter is unlimited. The first, on the other hand, restricts the subject matter to the community itself but leaves the sources unrestricted. However, it can be seen, in figure 1, that each definition intersects with the other two. For example, the

5. This definition was adapted by Wilkinson [19] on pp. 27-37 from the American Library Association Glossary (1983) definition. 


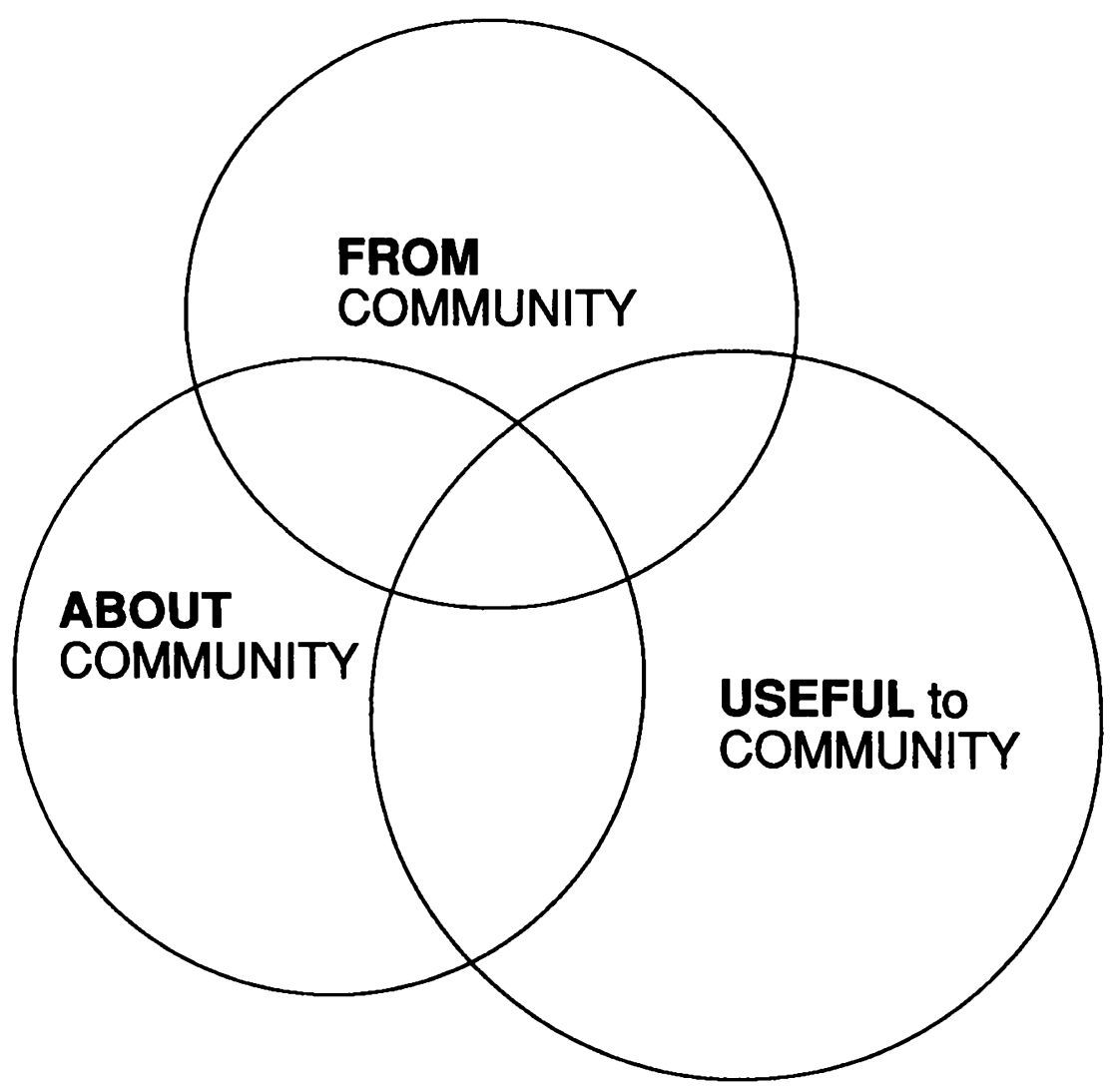

Fic. 1.-Comparison of definitions of community information

second definition includes both information about the community (which brings that definition into intersection with the first definition) and information useful to the community (which it brings it into intersection with the third).

The service providers in the community function primarily within the second definition: disseminating original information from within the community. As will be shown later, the definition of community information that reflects the mandate of the community network is the third and broadest definition of community information: all data that are flowing anywhere that is useful to a community. Of course, other organizations in the community also operate in that domain of this definition, most notably the public library. It would appear neat and tidy, then, if the remaining definition of community information (the first, data about the community) could be easily identified as the do- 


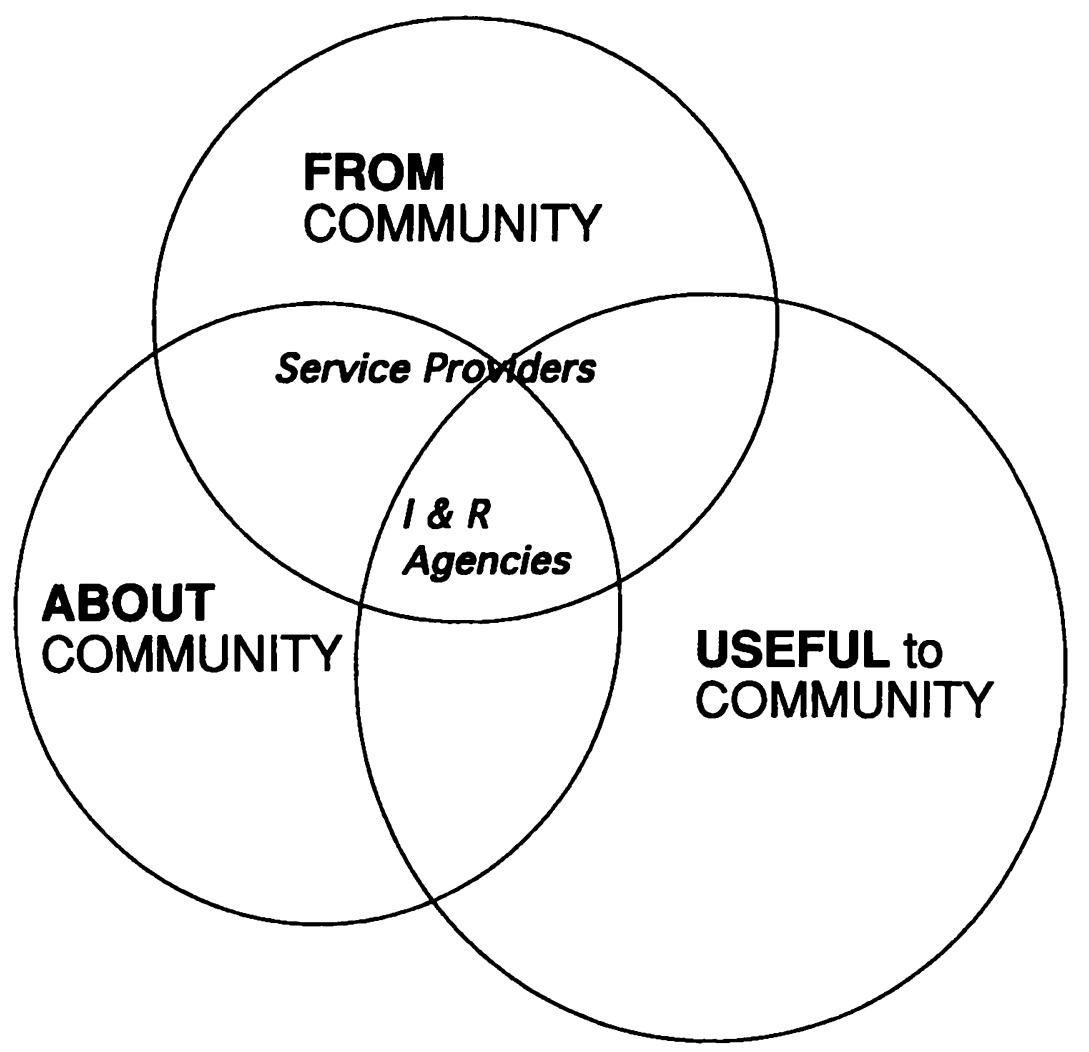

Fig. 2.-Comparison of I\&R agencies and community networks in the contest of definitions of community information.

main of the remaining type of organization in this examination, the $I \& R$ agency. However, our later analysis leaves little doubt that this would probably be to ascribe too large a domain to the I\&R agency. Rather, it would appear that the I\&R agency occupies a role at the epicenter of the three definitions: information about a community flowing from within the community that is useful to the community (see fig. 2).

Returning to the task of establishing a common context for one comparison, we examine the information process itself. Within the information process there are three key elements: acquisition, use, and dissemination, which "are all human processes. Technology is only a tool which aids in these processes at the directions of humans" [19, p. 43]. An important aspect of the information process model is that a player's role can change, depending on the situation. Therefore, players' positions in the information process are not static, but dynamic-they play 

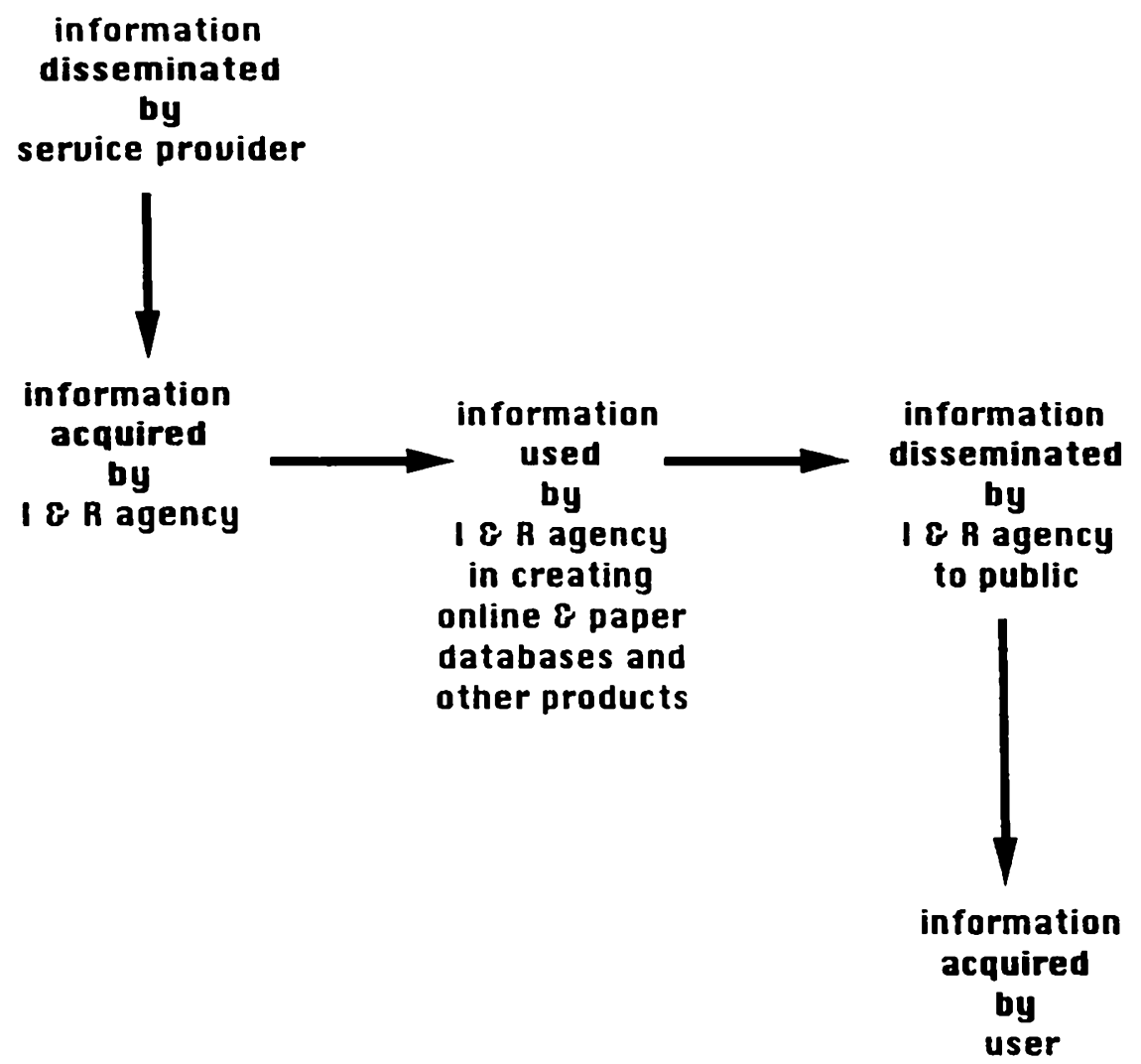

FIG. 3.-Role of I\&R agency

different roles at different times with respect to a given item of data. At one point they are on the acquiring end of an exchange and then may later disseminate that same data to another. This article will discuss a particular type of information process-the community information process-and those who play various roles in it.

The I\&R agency (through its employees) seems to be an active player in the community information process at all times (fig. 3). Information is acquired by the agency and then actively used by the employees of the agency in preparation for dissemination to the public.

Differences in the roles of the community network and the $I \& R$ agency appear inevitable as soon as one begins to consider the community network in this context (fig. 4). The people involved in the management of the network are not directly involved in the information process flowing through it. Once the system is in place, the system oper- 


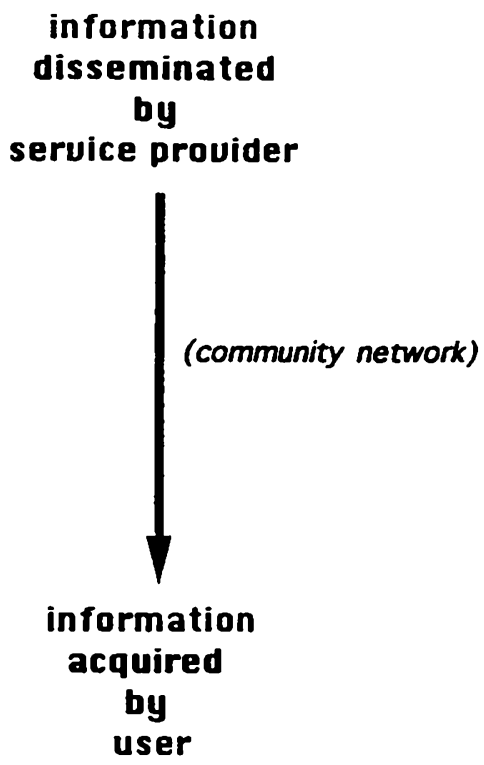

Fic. 4.-Role of community network

ators do not appear to be an integral part of the information processes that are occurring through the medium of the technology.

The analysis of the definitions of community information, developed from the general definition of information, and discussion of the community information process, a particular type of information process, lead to our hypotheses:

Hypothesis 1: Community information networks and I\&R agencies do not occupy the same roles in the information process since the community network, by definition, deals with a much broader scope of information than the I\&R agency.

Hypothesis 2: The two roles are directly related in some way because the area of information with which the I\&R agency deals lies completely within the boundaries of the scope of the community network, and yet must be distinct in some way because the scope of the I\&R agency is clearly bounded by a consistent definition that does not fully describe the role of the community network.

These hypotheses are tested in the remainder of this article.

Defining the Players

Analysis of the community information process being presented here involves four key players: I\&R agencies, community networks, service 


\section{I \& R AGENCY}

- Inquiry service

- Database

- Publications

- Social reporting

- Community consultation $\&$ education

\section{COMMUNITY NETWORK}

- Electronic mail

- Discussion forums \& news groups

- Community information

- Access to other databases

- Internet access (in some networks)

Fig. 5.-Comparison of services

providers, and users. I\&R agencies can be defined as those delivery "programs whose primary purpose is to maintain information about human services in the community and to link people who need assistance with appropriate service providers" [20, p. 202], and whose primary goal is "help[ing] people access social and human services information. Correct and accurate information allows people to make informed decisions, increases a person's independence and their ability to solve problems and enables them to participate fully in the life of their community" [21]. Simply put, I\&R agencies maintain and disseminate community information (exactly, it may be noted, as defined in the restricted domain set out earlier in this discussion) as their primary mission. The Alliance of Information and Referral Systems (AIRS), a North American association for I\&\&R agencies, states that an I\&R agency's main services or functions are to “(1) develop and update files about community resources in the human service area; (2) provide information over the phone about these resources and make formal referrals to the appropriate service agencies; (3) follow up with clients and service agencies to determine if the needed service was obtained and if it adequately met the need; (4) participate in community education activities; (5) engage in advocacy for the development of new human services; and (6) prepare statistical reports on service requests and undertake research on local needs to help community planners and funders" [22]. These functions can be summed as inquiry service, database, publications, social reporting, and community consultation and education [23] (see fig. 5).

Community networks have flourished across North America since the mid-1980s and their appearance has been described as "a quiet revolution ... penetrating the fabric of America's cities" [11, p. 24]. Many terms are used to refer to community networks-community- 
based information networks, community bulletin boards, public access networks, community nets, community computer systems, and Freenets, to name a few. The last term actually refers to a specific type that uses software developed by Tom Grundner at the National Public Telecomputing Network (NPTN) in Cleveland, Ohio [24]. The NPTN also provides guidelines and support to its community network members (similar to the support provided by AIRS to I\&R agencies). But what is a community network? Fundamentally, it "consist[s] of one or more computers providing services to people using computers and terminals to gain access to those services and each other" [9] - that is, in the terms developed earlier, providing access to data that are flowing anywhere that is useful to a community. Doug Schuler [14] expands this description, saying community networks are "intended to provide 'one-stop shopping' using community-oriented discussions, questionand-answer forums, electronic access to government employees and information, access to social services, email, and in many cases, Internet access," and adds the community networks are "intended to advance social goals such as building community awareness, encouraging involvement in local decision making, or developing economic opportunities in disadvantaged communities" [14, p. 39] -an objective not dissimilar to those of I\&R agencies (discussed above-see fig. 5). Special interest groups (SIGs), a popular community network service, are spaces on the computer used by persons or groups to post information they believe to be of interest. Serving an informal social networking function, a SIG can contain community information. Since this article is confined to an examination of formal channels for community information, it excludes discussion of the roles of newspapers, neighbors, corner stores, and SIGs in the provision of informal channels for community information.

Another class of players involved in the community information process, service providers, broadly includes all organizations, government departments, and groups who provide some type of service to the community. For our purposes, this definition would include, for example, a recreational club, such as a lawn bowling club, because its organizers operate a service for the public's benefit. Service providers play an important role in the community information process because they are primary sources upon which both I\&R agencies and community networks rely for acquiring information. Their agreement to participate in the information process is crucial if I\&R agencies and community networks are to have a useful product. (It may be noted that, in a certain sense, I\&R agencies and community networks are themselves service providers. However, in this discussion they are considered to facilitate access to other providers.) 
The final player is the individual user or the collective public. Within a community, many dynamic subpopulations may exist, and a user may be a member of any combination of subpopulations at one time. Recognizing these distributions and the demographic characteristics of user groups, service providers' programs are often tailored to fit the needs of specific groups, such as the elderly or the unemployed. Specific user groups are also created when service providers erect barriers (either purposely or inadvertently) to restrict wider public access to their services. Examples of barriers include geographic service area restrictions, limited hours of operations, imposed user fees, age restrictions, physical barriers, and the prerequisite of special equipment (such as computers) to access the service. Users of community information determine the sources and relative importance of the service providers, the I\&R agencies, and the community networks as information sources by the extent to which they consult any or all of them for information.

All four types of these players have power over the community information process, but they exercise control in different ways and to varying degrees. Their control varies from high to low, and its exercise from the subliminal or indirect to the obvious and stated. One area of control over community information is the user's decision either to use or not to use a particular service for accessing information. Another is the service provider's decision to provide information to an $I \& R$ agency or not. A third would be the community network's decision to charge a membership fee or not. These four players are directly involved in information flow activities. There are other players who can indirectly influence that flow through direct involvement with any one of these types of players. For example, a funding agency retains control over the receiving agency's services as a result of built-in requirements in the funding agreement. Both direct control and indirect influences on that control will be explored in the analysis of community networks and I\&R agencies that follows.

\section{Analysis: Where the Control Lies}

It will be recalled that the six facets to be discussed in this connection are (1) agency ownership and governance, (2) funding, (3) information flow, (4) access, (5) ownership of information, and (6) quality control. During the analysis, each facet will be examined and the locus of control along that dimension will be identified for an I\&R agency and for a community network. 


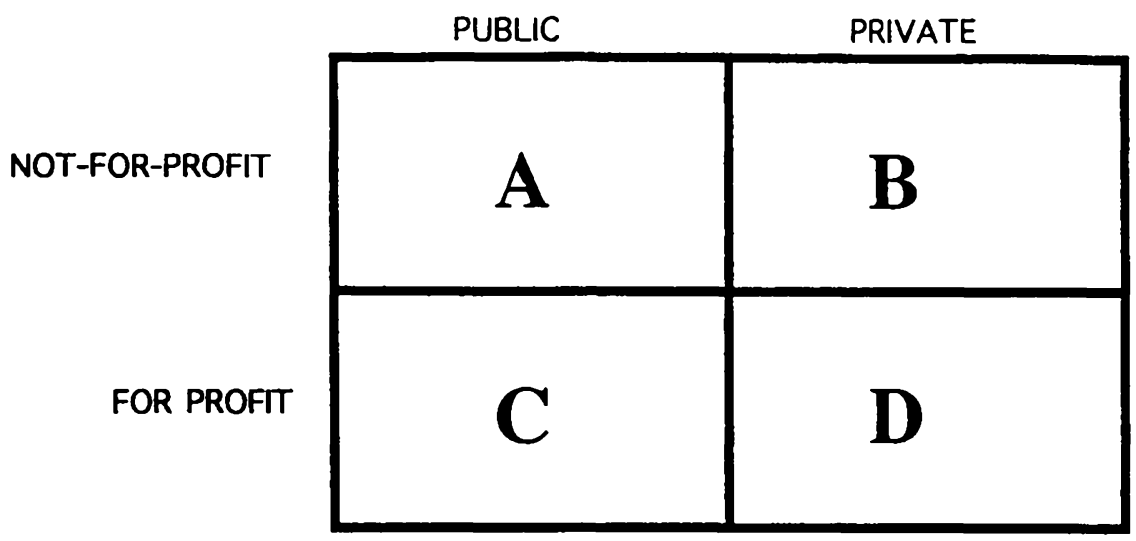

Fig. 6.-Organizational ownership: economic sectors matrix

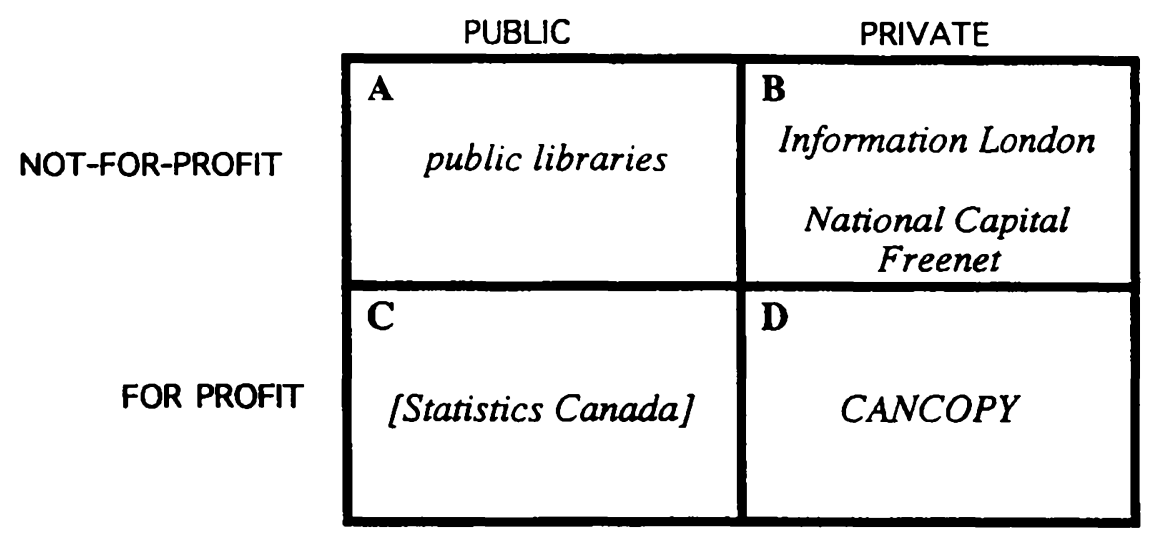

Fig. 7.-Economic sectors matrix, with examples

\section{Facet 1: Agency Ownership and Governance}

The first facet for analysis is ownership of the organizations involved and their governance. An organization can be owned either by private individuals or corporations ("private") or by governments ("public") ${ }^{6}$ In either the public or the private sector, the organization can be operated on a "for-profit" or a "not-for-profit" basis. These four possibilities are illustrated in figure 6.

If an organization is in the public sector (quadrants $A$ and $C$ of figs. 6,7 ), then it is owned by, and accountable to, the general public. Therefore, it is the public, through government and legislation, that

6. Also known as "crown" in Canada and other constitutional monarchies. 
controls whether such an organization exists, its purposes and services, and how it is funded. The public library, for example, is an information organization clearly within quadrant $A$ (see fig. 7). The Ontario Public Libraries Act [25], for example, states in s. 23: "(1) A board shall not make a charge for admission to a public library or for use in the library of the library's materials. (2) Every board shall allow the public to, (a) reserve and borrow circulating materials that are prescribed or belong to a prescribed class, and (b) use reference and information services as the board considers practicable, without making any charge." The identification of organizations in quadrant $C$, the "for-profit/public" sector, may be more contentious. However, it is argued here that the implementation of "cost recovery" initiatives has effectively placed some organizations in that sector. The Policy Manual of Statistics Canada [26, pp. 1-3], for example, contains the following statements (among others):

Standard products and services are provided to clients on the basis of predetermined fees and charges with due regard, where applicable, to the price of similar products from other sources.

The rationale underlying the fees and charges for [standard products and services] is designed to recover the full cost of making available such services and products to their anticipated clients over and above the costs covered by Parliamentary Appropriations. Such fees and charges will take into account, where appropriate, the price of corresponding products.

Publications: in their collectivity [emphasis in original], the prices established for publications are based on recovering the agency's full costs of making survey data available in publications format.

When an organization belongs to the private sector, on the other hand, control ultimately rests within its own structure, as further discussed below. Current examples of private organizations are the Canadian Living Foundation, which funds the "Breakfast for Learning" program (a literacy charity) in quadrant $B$ (not for profit), and the Canadian Copyright Licensing Agency (formerly the Canadian Reprographic Collective), known as CANCOPY, in quadrant D (for profit).

The location of an agency within the matrix, as shown in figure 7, is a public policy decision, and particular agencies can be relocated from time to time. For example, the forerunners of the public libraryMechanics Institute libraries-were in the private sector. While most I\&R agencies and community networks are currently located in quadrant $B$-the private not-for-profit sector-Schuler [14] makes the point that community networks could be moved when he says that instead of using the private not-for-profit structure ( $B$ in fig. 6 ), a community network may be organized as a nonprofit/government cooperative 
venture (a combination of $A$ and $B$, like CANARIE), a governmental organization $(A$ or $C)$, or a for-profit organization $(C$ or $D))^{7}$ Public organizations are mandated by government to provide specific services. Since they are currently located in the private sector, I\&R agencies and community networks do not have to conform to any legally imposed guidelines, aside from the statutes governing their types of incorporations, leaving aside the question of a regulatory framework that can be imposed by government in the private sector but has not been directly imposed with respect to information flow in our cases.

Information London [27] is in quadrant $B$, the private not-for-profit sector, because it is incorporated in Ontario and is specifically governed under The Corporations Act [28], The Charities Accounting Act [29], and The Charitable Gifts Act [30]. These acts restrict how monies can be acquired by the agency, how its executives can be paid (only expenses incurred through the performance of agency-related duties), the roles of its directors, and how its properties can be distributed in case of the agency's dissolution. The bylaws of the agency itself specify the constitution and operations of its board and the responsibilities of its board members. The National Capital Freenet in Ottawa is also a nonprofit Ontario corporation [31] (in quadrant $B$ ), and its bylaws specify a constitution for its board similar to that of Information London. In this respect I\&R agencies and community networks do not differ on locus of control.

Governance, the other half of our first facet, is the management structure imposed on an organization that dictates who is financially and legally liable for the organization and who ultimately controls its operations. Schuler lists the areas a community network's governance must be involved with: "the day to day operations, including system maintenance and administration, as well as community outreach, fundraising, and participation in the political process" [14, p. 46]. Under the bylaws of the National Capital Freenet [32], the powers of one community network's directors to make decisions are described in items 18-20 as follows:

18. The directors of the corporation may administer the affairs of the corporation in all things and make or cause to be made for the corporation, in its name, any kind of contract which the corporation may lawfully enter into and, save as hereinafter provided, generally, may exercise all such other powers and do all such other acts and things as the corporation is in its charter or otherwise authorized to exercise and do.

19. The directors shall have power to authorize expenditures on behalf of the corporation from time to time and may delegate by resolution to an officer

7. CANARIE stands for the Canadian Network for the Advancement of Research, Industry, and Education. 
or officers or executive committee of the corporation the right to employ and pay salaries to employees. The directors shall have the power to enter into a trust arrangement with a trust company for the purpose of creating a trust fund in which the capital and interest may be made available for the benefit of promoting the interest of the corporation in accordance with such terms as the board of directors may prescribe.

20. The board of directors shall take such steps as they may deem requisite to enable the corporation to acquire, accept, solicit or receive legacies, gifts, grants, settlements, bequests, endowments and donations of any kind whatsoever for the purpose of furthering the objects of the corporation.

Upon comparison, it appears that the powers and duties of Information London's board of directors (as outlined in sec. 6 of its bylaws [27]) are quite similar to those held by the directors of the National Capital Freenet.

Therefore, our analysis concludes that ownership and governance are the same for Information London and the National Capital Freenet: both organizations belong to the private, not-for-profit sector, and their boards exercise similar powers and duties.

\section{Facet 2: Funding}

The second facet, funding, plays a major role in controlling the community information process. If we define funding as the sources and means of financial support an organization uses to build and maintain its services, then it is obvious how the amount of funding can affect an organization. Obviously, in a general way, funding sources (whether they are government programs, other nonprofit associations such as the United Way, private donations, or revenue earned through costrecovery schemes such as user fees) control the range and extent of the services an organization can provide. A specific funder may also be able to dictate specific terms in the funding. For example, government may offer program funding on the condition that it be used to provide services to a particular group, such as seniors, or that it only can be used for creating a database and not for operating an information counseling program.

Major funders of I\&R agencies include "local United Way programs, libraries, city or county government or the military" and "many private, non-profit organizations operate on a contract with other community entities"' [33, p. 2]. Information London is financially supported by the United Way of Greater London, the City of London, the Province of Ontario, and Canadian federal government ministries [34]. During 1992 the National Capital Freenet operated its services using mostly federal and provincial seed grants, donations, fund-raising drives, and line sponsorships [35]. In general, few community networks receive government funding, and therefore they depend, as Steve 
Cisler [9] notes, "upon a constantly changing group of partners, corporate angels, foundations, and user fees and donations to keep going." Charging user fees is antithetical to the bases upon which these networks are established, and since community networks "are free of charge or have a very low charge" [14, p. 41] user fees are not a source of substantial funding. Neither Information London nor the National Capital Freenet charges user or membership fees, though Freenet members are encouraged to enclose a donation (of any amount) with their applications. Schuler observes that "funding for community networks so far has been sporadic and unreliable. Equitable, reliable, and replicable funding approaches from indirect and/or direct participants must be developed" [14, p. 48]. The early history of I\&R agencies described by Levinson [18] reports similar funding difficulties for I\&R agencies. It is clear that community networks are seeking funding from the same sources that $I \& R$ agencies already depend upon.

\section{Facet 3: Information Flow}

The third facet, information flow, refers to the pathway information follows as it moves through the community information process from source to user. Wilkinson [19] describes information flow in terms of volume and direction, where direction is the actual pathway the information follows and volume is the amount or quantitative measure of the information in movement. Since, as was also the case in Wilkinson's original study, reliable data for describing volume is unavailable, only flow direction is examined here. Information flow is an intrinsic part of the community information process described earlier. Figure 8 shows the potential paths or flows of information and the information process in each of our two settings. Note that the process is cyclical in that once users obtain community information from the I\&R agency or community network, they may then contact the service provider directly for some service or product. The cycle then continues as service providers alter their services based on their users' expressed needs, and these information changes must in turn be made in the community information databases. The guidelines and operational documents issued by I\&R agencies [36] and community networks confirm that information flow can be modeled precisely as shown.

Figure 9 shows the actual flow of information in the Information London setting and expands on the I\&R agency role shown earlier (in fig. 3). First, Information London staff collect data from service providers such as Fanshawe College, the London Centre for the Deaf, and the Ontario Ministry of Housing. Next, staff organize the data and use them to create online and paper databases and other information products. Then the information is disseminated through various means 


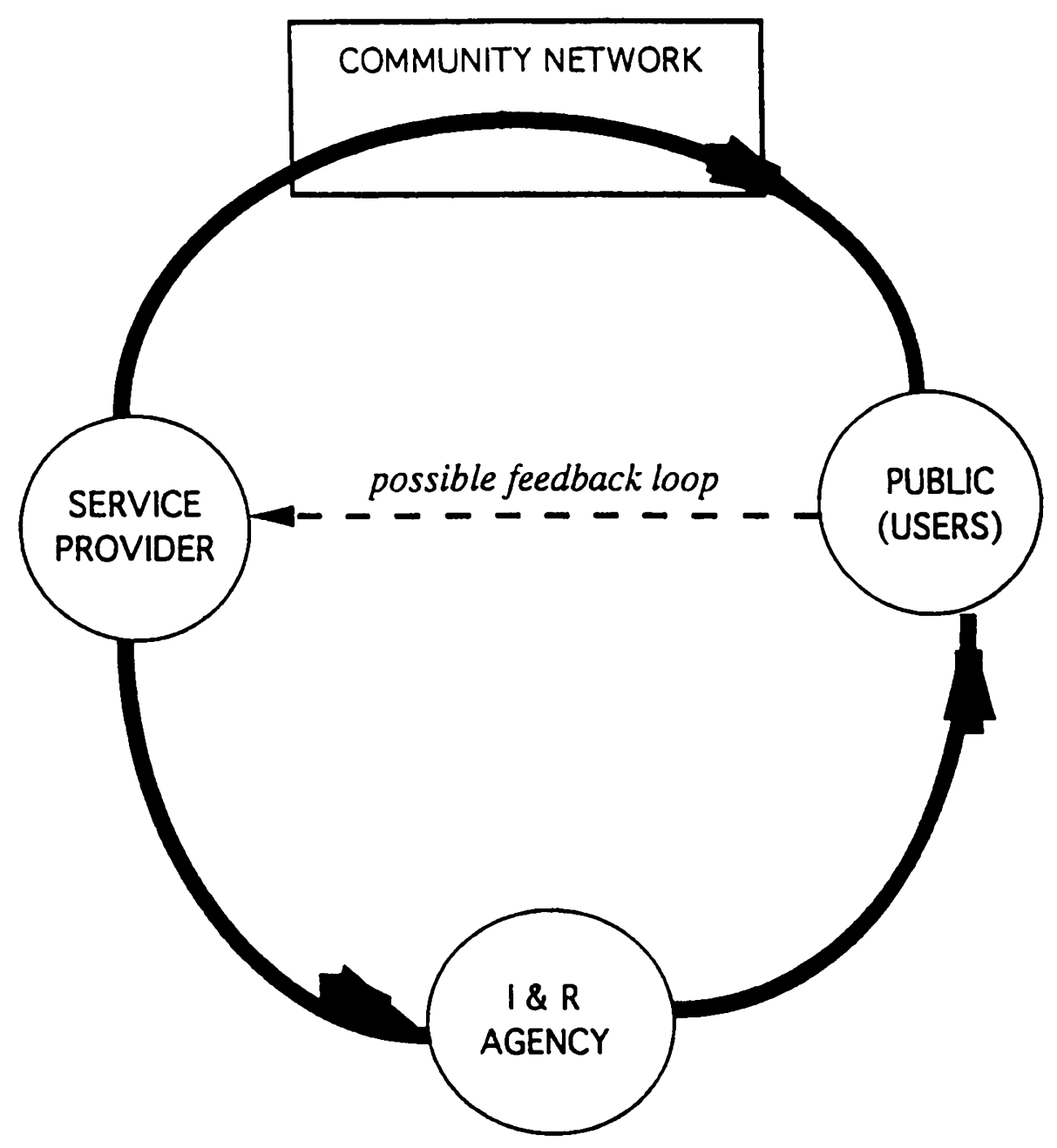

Fig. 8.-Information flow

(described earlier) to the public, who may in turn contact the service providers. During 1993-94, Information London staff "responded to 45,000 telephone inquiries, provided in depth information support to over 1500 professionals through [their] Community Service Directory and SkillSearch Directory, and published 51 newspaper columns and over 30,000 brochures" [34].

The pathway information assumes in the community network model is described as follows: "Each [community agency] can now share a 


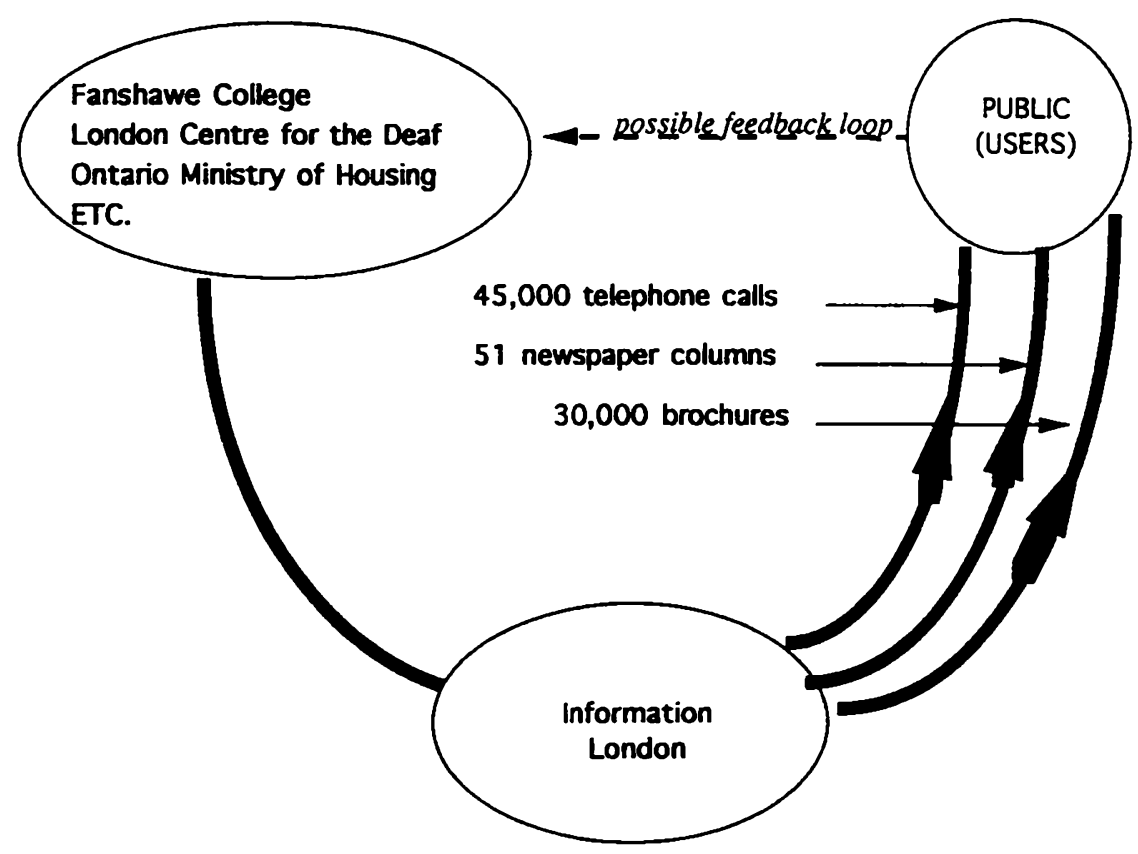

FIG. 9.-Information flow involving Information London

single, cost-effective, interactive and sophisticated computer facility. A Freenet permits each organization [information provider] to have its own dedicated space on the central network, and to determine autonomously how it is used. The network is assessed by a common telephone number, much like 911, and provides 'one-stop shopping' for all those seeking community information" [37]. Following this description, the flow of information originates with (is disseminted by) the service provider, is held or stored on the Freenet, and then is accessed by the public. The actual flow of information in the National Capital Freenet setting is shown in figure 10. Service providers, such as Amnesty International, Scouts Canada, and the City of Ottawa, post information about themselves and maintain their own areas. Users then access the information by dialing into the system. They can later choose whether to contact the service provider directly for additional information or services. As of October 1994, the National Capital Freenet had over 27,800 members, and between August 28 and October 15, 1994, 10,931 users logged into the system [38]. The distinction between members and users of the Freenet is that members sign a user agreement and are entitled to use additional features of the Freenet, such as having an 


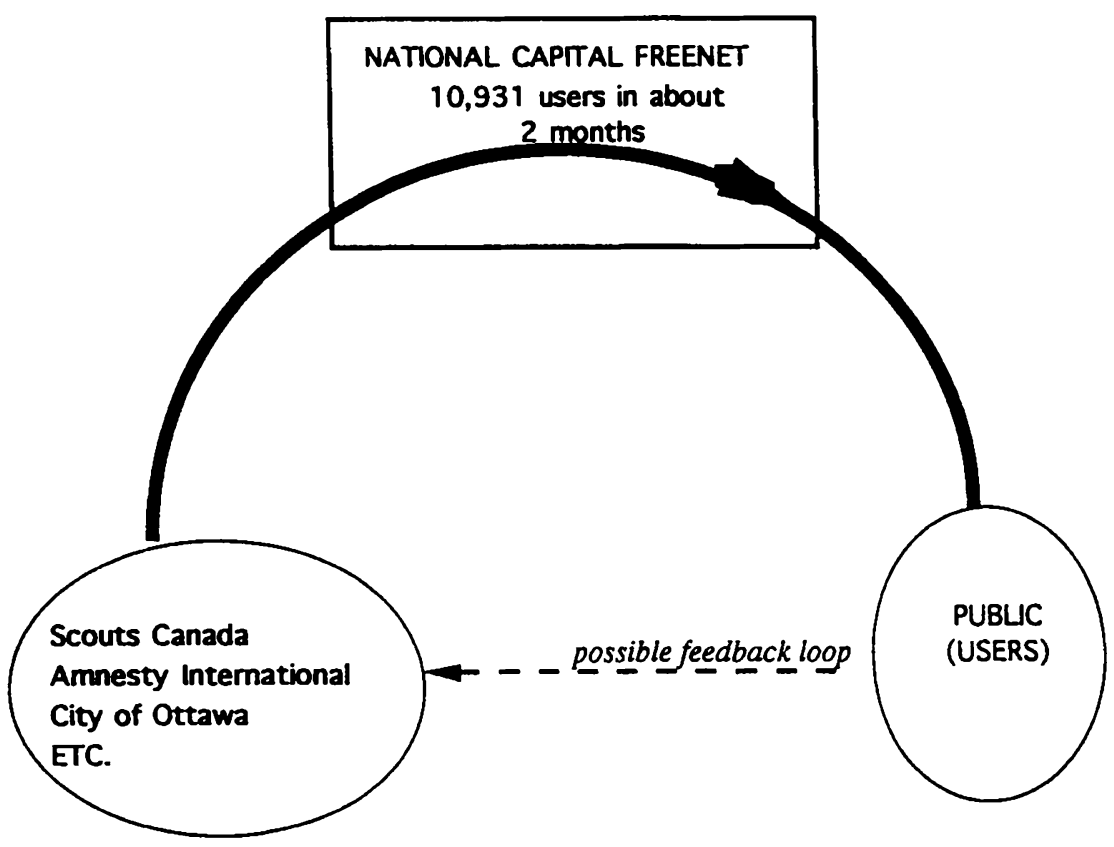

Fig. 10.- Information flow through the National Capital Freenet

E-mail account. Often when gathering statistics no distinction is made between members and users, as a member is considered a user of the system. But a user is not necessarily a registered member. Also, the figure 10,931 includes multiple log-ins by the same users. It does not represent the number of individual users but, rather, the number of demands on the system. The Information London inquiry statistics also reflect demand rather than individual users. But Information London would also need to be able to quantify those served by its directories, brochures, and columns in order to do direct comparison with the Freenet statistics.

Extending the idea from the information process discussion that all members of a community, be they individuals or organizations, can function as information acquirers, users, or disseminators at different times, we can see from the matrix in figure 12 how various combinations of roles in acquiring and disseminating information are possible for service providers, users, and those who mediate information between them. ${ }^{8}$ The bare matrix (fig. 11) illustrates how information can be acquired from and disseminated to any combination of classes of

8. The use of matrixes is further explained in Wilkinson [19], pp. $49 \mathrm{ff}$. 


\section{DISSEMINATION FROM:}

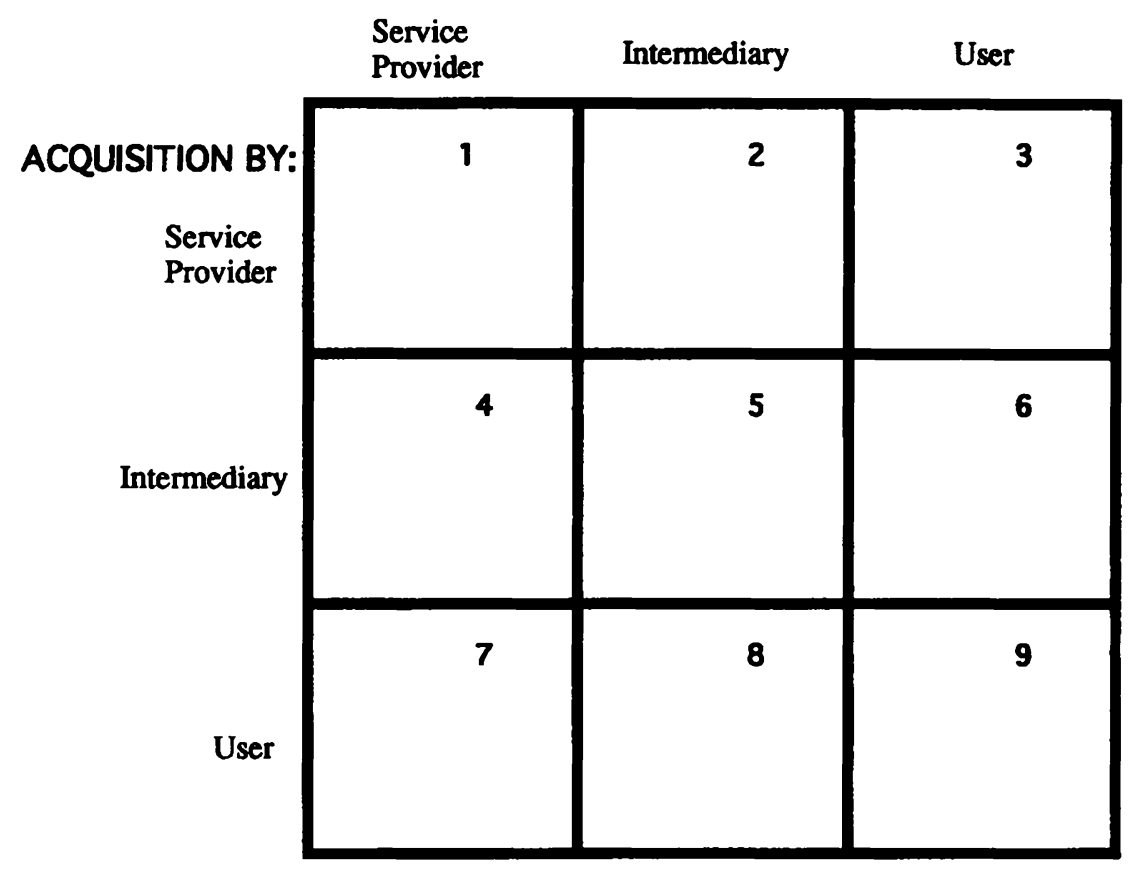

Fig. 11.-Matrix of information flows

players, including a player acquiring information from and disseminating information to another player within the same class. For example, an individual user may acquire/disseminate information to another user. However, when one considers the definition of community information process developed earlier in this article, it becomes evident that not all cells of the matrix are relevant to this discussion. Figure 12 indicates the cells involved in the community information flow being analyzed in this article. In the first analysis only three are relevant: cells 7 (service provider to users directly), 4 (service provider to intermediary), and 8 (intermediary to user). Cell 3 can be involved in the subsequent feedback interaction between users and service providers (described above), which subsequently filters back into cell 4 again.

Each player involved in the information flow can exercise control from at least two different perspectives: as an acquirer and as a disseminator. For example, if a service provider chooses not to cooperate with an acquirer and withholds information, then the acquirer has nothing to process or use. In other words, the service provider can impede the 


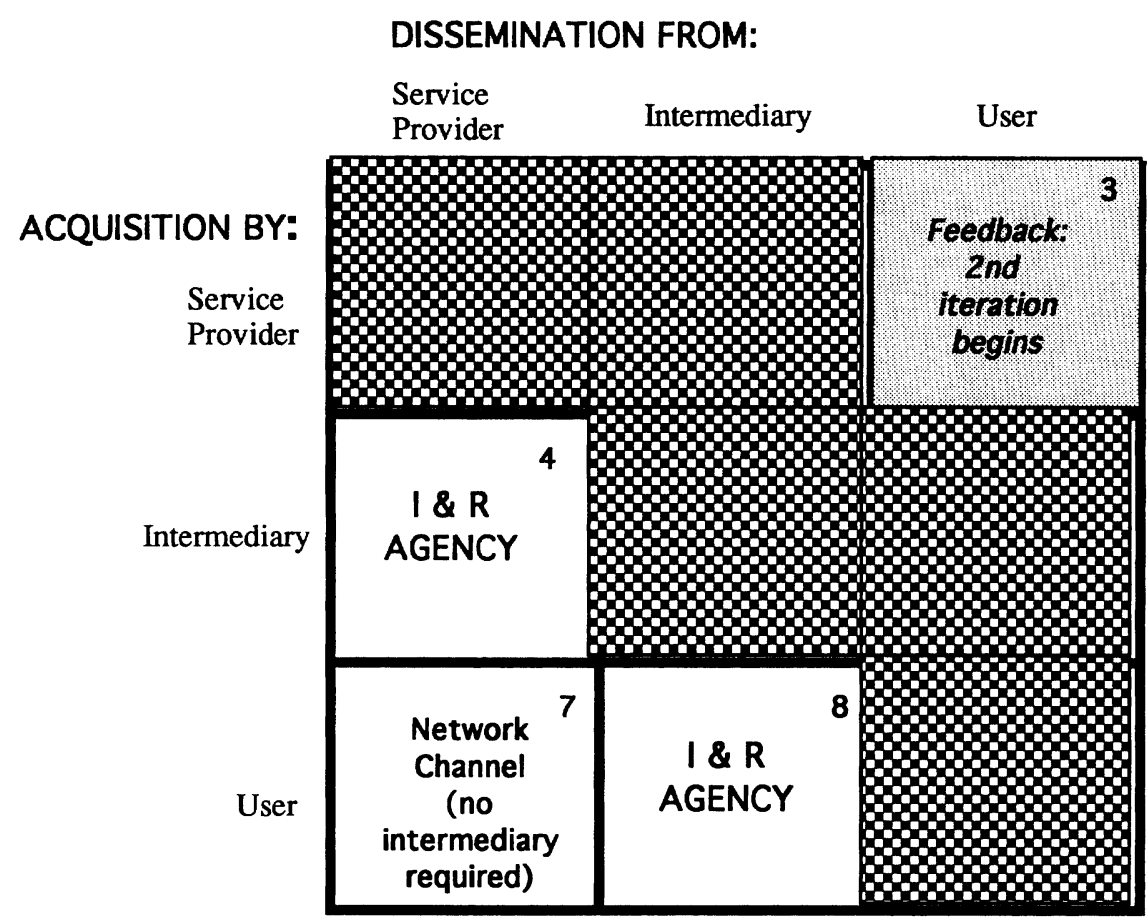

FIG. 12.-Matrix of community information flows

flow of the information through one channel by preventing it from being acquired through that channel. In another scenario, the user may choose not to acquire the information disseminated by the I\&\&R agency or through the community network. Here the information flow is abruptly halted on that path, as there is nowhere for the information to flow. Bryn Geffert reports such a situation in his case study of the Freenet P.A.T.H. (Public Access to Heartland) in the local library system where "the lax attention given to some of the Freenet [was] a serious hindrance to patron enthusiasm and use"' [6, p. 94]. In his description of the Blacksburg Electronic Village community network, Robert Heterick [10] predicts: "One of the principal measures of success of the project [community network] will be the number of citizens who elect to participate" (direct acquisition by users). Writing about the Wisconsin Health Information Network (WHIN), Dave Jensen [39] also makes several remarks that can be generalized to community networks. He emphasizes the importance of having a broad range of groups participate in the network (direct dissemination by service providers), how "the critical challenge facing [a network] is gaining the 
acceptance of the community," and that collaborative efforts within the community are necessary to enable the free flow of information. Even the initial purpose of WHIN, Jensen writes, was "to improve the flow of information."

Both the information flow diagrams (figs. 9, 10) and the information flow matrix (fig. 12), model the roles of I\&R agencies and community networks and indicate a fundamental distinction between the two: the community network is not an intermediary in the information flow process. It plays no part in the human processes of choice in acquisition or dissemination. It is a channel available to facilitate flow-like CANADA POST. Indeed, it does not appear in the matrix model as an active participant. By contrast, the I\&R agency does exercise control in acquisition and dissemination and is therefore reflected as a participant in our matrix. In figure 8 , the I\&CR agency appears as a node in the process, whereas the community network is just one possible channel.

In sum, information flows in the same direction in both the I\&R agency and community network settings. However, control over the information resides with different players in the two settings. As quoted above, in the Freenet model, each organization has autonomy over its information delivery over the network, which signifies the absence of control on the part of the network operators. On the other hand, in the I\&R agencies, as is further discussed below, a mandate to maintain quality means that the agencies claim the right to control the information in their hands.

\section{Facet 4: Access}

Access, the fourth facet, is defined as how users can obtain information. The way access is provided can create different user groups and therefore be used as a mechanism for control. A user being unaware of a service is an initial barrier to obtaining service. Of course, we assume in this analysis that potential users are aware of these two agencies and their purposes.

Once the agencies are known, who controls access to the information held by I\&R agencies and community networks? Community networks strive to provide direct open access to the public. However, in order to utilize this access, users must have certain capabilities: access to a computer with communications ability, which implies they must possess both the requisite financial resources and a certain degree of technological expertise (or task knowledge) in order to use the equipment and navigate the system. In discussing community networks, Heterick says that "Deployment choices that would limit the number of participants are extremely poor choices and contravene the intent of the [net- 
work]. Such choices might be in the infrastructure, the user interface, or the pricing strategies" [10, p. 242]. Schuler adds that "to promote universal use, community networks must be easy to use, easy to access, and free of structural barriers to their use. In addition, the systems must be reliable, the user interface intuitive and nonintimidating, and special-purpose interfaces must be developed for those with special needs"' $[14$, p. 48]. To facilitate wider public access, the National Capital Freenet [40] has prepared a ranked list of locations in which it will place donated equipment as received: (1) public libraries, (2) local government offices, (3) educational centers, (4) hospitals, (5) community health and resource centers, (6) community recreational facilities, and (7) nonprofit organizations that serve the community (presumably including I\&R agencies). While such availability may enhance public access in one respect, the user must still have that basic level of technological skill. Control over access to both community networks and I\&R agencies is also limited by the number of phone lines operated by the agency-but the number of phone lines is more central for the community network, since the I\&R agency has a more varied range of modes of access. Beyond this initial access, the community network has no control over users. Anyone with a modem or mainframe terminal can access the system from anywhere in the world. Indeed, a higherorder access problem for users exists in the community network environment in that the network does not control how the information posted is to be organized, and therefore each posting service provider is free to adopt its own model.

In the traditional I\&R setting, on the other hand, users contact an intermediary or inquiry counselor by telephone, by mail, or in person (users are also served through publications). However, access can be restricted in a number of ways: users without access to a telephone, fewer telephone lines and/or fewer counselors than demanded, lack of literary or lack of circulation of product or publication, or inability to access the agency in person (transportation or hours of operation limiting access). On the other hand, users do not require any special or expensive equipment and there is no specific task knowledge involved, no complex system to navigate. As distinct from the community network, it is possible for an I\&R agency to impose service area restrictions or geographic boundaries such that only users who have membership within a particular geographic area or are members of a particular group are entitled to services.

At Information London users can physically access services from Monday to Friday, 8:30 A.M. to 4:30 P.M. for a total of forty hours a week [21]. The National Capital Freenet, however, provides access to its ser- 
vice twenty-fours a day [31].${ }^{9}$ Information London provides services in English (efforts are made to serve non-English speakers, but the service is not immediate); The National Capital Freenet provides its information in both of Canada's official languages: English and French. Information London's main service area is London, although it would not refuse service to a user outside the area. The critical point is that the I\&R agency, Information London, could refuse service to a user outside its area if it chose to do so (and makes this decision on a case-by-case basis), whereas anyone can access the National Capital Freenet provided they have Internet communications or a modem and the requisite telephone link. Access cannot be restricted on a case-by-case basis by the network. Based on the foregoing analysis, we can conclude that control over access generally rests with the I\&R agency. In the community network model, access is user controlled once certain technological barriers are overcome.

\section{Facet 5: Ownership of Information}

The fifth facet for analysis is ownership of the information involved in the process. The owner of information is defined for these purposes as the organization or person(s) who is in possession of information and is legally entitled to manipulate and dispense the information at will. In the sense that community information exists within a community and therefore belongs to it, community information is not privately owned. ${ }^{10}$ It would appear that ownership of community information can occur only through the value-added attributes created by a player in the dissemination of information in a fixed form-it is the enhancements made to the information, while it is being used in the information process, that are actually owned. For example, enhancements are made to community information as it is created into a publication. The expression of the information in a fixed form can give the agency copyright protection, a form of intellectual property, in the publication (though generally not in the data it contains). ${ }^{11}$ For instance, Informa-

9. Taylor Walsh [41] makes a similar distinction between the accessibility of libraries and community networks, in noting that the flow of information in an online setting is not restricted by time or place.

10. Therefore, by definition, it cannot be considered as falling within that class of information over which an organization could claim "ownership" rights by virtue of its confidentiality or trade secret nature. It would be possible for these facilitating organizations to own such information, but such information would not be the community information with which this article is concerned.

11. The recent implication of the North American Free Trade Agreement has caused Canada to appear to broaden its definition of works that can be copyrighted (and therefore narrow the scope of circumstances in which ideas and facts can be freely copied). A definition 
tion London holds copyright to its Community Services Directory [23]. Database designs and taxonomies used for indexing community information records are other examples of enhancements or packaging of information that can entitle employers or the creators to copyright or "ownership" of that information. Whoever owns the organization (as defined earlier) has control over the ownership rights associated with the information held by that organization. The organization has the power to let others use the information over which it holds intellectual property rights-for example, to reproduce its database structure or reproduce one of its paper publications.

In a community network setting, the agency that posts the information has created that "work" and therefore owns the intellectual property rights to that work (absent any other agreement). The service agency "owns" it and is responsible for maintaining it: "the Freenet is a shared platform with each organization having a large, dedicated space on the system and autonomously determining how it is used" [31].

The National Capital Freenet itself does attempt to control the flow of information from service providers in one other way. Item 3 of the National Capital Freenet "User Agreement" [44] states: "All information services and features contained on the National Capital Freenet are intended for the private use of its patrons, and any commercial or unauthorized use of those materials, in any form, is expressly forbidden." This clause would appear to attempt to restrict the use to which recipient users can put information disseminated by the service providers through the freenet. Since users do not pay to access the Freenet, it is difficult to imagine that a court would find enough exchange to make clause 3 between the Freenet and its users a legally enforceable agreement. That being the case, since the Freenet does not hold copyright to the works contained in it, it would have no ability to stop reproduction or copyright protected uses of the information it transmits. Only the copyright holder, the service provider in our analysis, would have the right to do that. The National Capital Freenet also reserves the right to view all material that is posted on the network and reserves the right to remove anything it believes is inappropriate. Item 2 of their "User Agreement" [44] states: "2. That the National Capital Freenet reserves the right to review any material stored in files or programs to

of "compilation" was added to Canadian law, which includes "a work resulting from the selection or arrangement of data." See the Copyright Act, Revised Statutes of Canada 1985, c. C-42 as amended by Statutes of Canada 1993, c. 44 s. 53(3) [42]. For a full comparison of Canadian and American law in this area, see Margaret Ann Wilkinson and Ellen Kozak [43]. 
which other users have access and will edit or remove any material which the board, in its sole discretion, believes may be unlawful, obscene, abusive, or otherwise objectionable." The "ownership" rights of service providers to own and control their information are limited, therefore, by this item 2. In sum, the Freenet does not acquire any ownership rights itself by virtue of item 2; only the right to remove is given, not the right to use, whereas since an I\&R agency creates its own works out of information it receives from others, it has ownership in the intellectual property rights related to that information in the new "works."

\section{Facet 6: Quality Control}

Quality control, the final facet for analysis, is defined as the measures and standards imposed by an organization to ensure that its products and services meet a targeted level of quality. These standards can range from high to low, and the degree to which agencies enforce them can also vary widely. There are three main aspects of quality control for community information: (1) accuracy-ensuring that all the information maintained and disseminated is error free; (2) currency-ensuring that all the information is up to date; and (3) comprehensiveness or completeness-ensuring that all relevant information is collected, both within a single agency (service) record, such as a local food bank's, and within a particular subject area, such as child care. In an I\&R agency setting, control over these standards lies entirely with the I\&R agency, which decides what and how much information will be collected and from whom, how the information will be maintained (that is, database management), and to whom and how it will be disseminated. The I\&R agency assumes full responsibility for the quality of its information. This is often effected by issuing an expiration date on all disseminated information (that is, the user is informed of the date as of which the information is considered current) and by updating all agency records according to a prescribed schedule.

Maintaining a high-quality and comprehensive inventory of community information is no small task. "The collection of local community information is often difficult," as L. B. Woods and Jon Walker explain, because "investigating sources, collecting and verifying data, organizing information, and maintaining its currency, and disseminating the information requires skill and involves an enormous expenditure of time and energy" [45, p. 393]. The level of difficulty and work involved depend upon the standards an organization accepts. I\&R agencies adhere to very strict and high standards of information management, and as a result are known for the quality of their information. For performing basic I\&R services, AIRS members use criteria governing seven 
functions: (1) classification system, (2) resource file, (3) inquirer data collection, (4) data analysis and reporting, (5) training, (6) promotion, and (7) access to service [36]. Each function is explained in great detail in the standards that specify acceptable levels of performance, but AIRS clearly states that the onus is on the I\&R agency to ensure that minimum standards for information management are practiced. While AIRS does not have an accreditation process for I\&R agencies, the Association of Community Information Centres in Ontario ${ }^{12}$ is in the process of creating one. Because these standards make them wholly responsible for the content and quality of their information, I\&R agencies maintain full control over this domain. They are limited only by the participation of the service providers who are their sources.

In a community network setting, on the other hand, control of such standards typically rests largely with the service providers. Schuler says that "no central authority of any kind establishes what information is available" on a community network [14, p. 40]. For instance, a community network may officially (or unofficially) adopt the motto "Host it and post it," where the community network does not exercise any quality control measures or make any claims about the posted information. There are several key phrases in the National Capital Freenet documentation that describe the freedom and control service providers have over their information. In the document "The Context of Public Access Community Networks" [37], its authors state "A Freenet permits each organization to have its own dedicated space in the central network, and to determine autonomously how it is used. . . . A Freenet allows each organization to maintain up-to-date information about its own services and staff. ... [A Freenet] creates a partnership, a shared responsibility between the community and existing social institutions for developing and providing timely information." ${ }^{13}$ The onus for observing quality control criteria rests solely on the service provider, and there is no one to ensure that this is carried out. ${ }^{14}$ While some service providers include the date on which they posted their information, it is not uniform practice. It is interesting that one agency that does date

12. An umbrella organization for Ontario I\&R agencies that represents over seventy Community Information Centres.

13. This description also reinforces our earlier argument that the community network is not a node in the community information process but is, rather, a channel facilitating communication between the existing social institutions (service providers) and the community (the users or public).

14. Walsh [41] expresses concern over the situation where technology enables information providers to scan information from a text source and easily make it available on a system, but there are no checks to ensure that the information provider will follow copyright laws or will check the information for accuracy first. 
its posting and revisions on the National Capital Freenet is the Community Information Centre of Ottawa-Carleton. The entry describes the I\&R agency's services and gives the subjects its database covers. However, the actual community information maintained by the I\&R agency is not accessible through the National Capital Freenet. Users have to contact the I\&R agency directly for information. In these cases, users accessing the services had best heed the admonition caveat emptor (buyer beware). Michelle Gauthier [46], in "The Non-profit Association's Guide to the Internet," writes that "Your association will be singularly responsible and/or liable for the information and services posted on your section of the Freenet board," and adds in a footnote that "the National Capital Freenet ... would not be liable for any false information provided by either your organization or your members on the Freenet Board. Participation and use of information obtained on the Freenet is entirely at the user's risk."

What control a community network does choose to exercise is generally derived from the internal written agreements between it and its service providers. In any event, the community networks often protect themselves from liability by stating in their user agreements that they are not responsible for the accuracy of the information. The National Capital Freenet's "User Agreement" [44] argues that the network intends quality control to rest with the service providers. For instance, sections 4 and 9 state:

4. That all information contained in the National Capital Freenet is placed there for general information and entertainment purposes and is, in no way, intended to refer or be applicable to any specific person, case, or situation.

9. That the information provided on the System is offered as a community service and is not a substitute for individual professional consultation. Adequate professional guidance for making important decisions cannot be provided through an electronic format of this type. Advice on individual problems should be obtained personally from a professional.

Again one must question the effectiveness of such agreements, where access to users is free and unrestricted. Such declarations may not absolve the network of liability should the user suffer as a consequence of relying upon the information. On the other hand, there is also a possibility that liability for information provision will fall on the service provider. This question of liability for information provision is an area of the law that is evolving in every jurisdiction (see, for example, Martha Felsky [47] and Barry Sookman [48]).

Of course, where an organization claims to control quality, the level of adherence throughout the organization to the quality control mechanisms will be what actually affects flow. If, in fact, an organization's 
products or services are of poor quality, whatever its intentions, the user will not use that organization to obtain community information. In that event, the flow of information available through that I\&R agency or community network would be decreased correspondingly. The bottom line is that a facilitator must meet its users' expectations in order to continue being used by information seekers. That use will in turn reinforce the service provider's reliance on that facilitator in dissemination.

Woods and Walker [45] earlier described the intense effort required to maintain a quality information base. This work in an I\&R agency is performed by staff who are highly skilled and knowledgeable in that area. There is a great contrast between this and the information management skills Freenets expect of the service providers with whom they expect to maintain quality information. Gauthier [46] describes the type of training a service provider can expect to receive from the network to help in the information manager role: "As for the staff member(s) and/or volunteer who will be responsible for transferring and updating your association's files on the Freenet, these individuals will need a half-day training session to master the basic transfer commands." The National Capital Freenet (as apparently, from Gauthier's perspective, all Freenets) does not provide its service providers or information posters with any sort of information management training in the sense of teaching them about the quality of information. Instead, it offers a very brief training session on the technical aspects of how to transfer and update files.

We conclude that the I\&R agency has full control over the quality of its information in all three aspects: accuracy, currency, and completeness. In the community network setting, on the other hand, the quality of the information is deliberated virtually to the control of the service provider who posts the information (although in the case of the National Capital Freenet, the network does retain ultimate control over whether a piece of information remains posted, according to item 2 of its "User Agreement" [44]).

\section{Discussion and Implications for Service Delivery}

At the beginning of this article, two reasons were offered for exploring this topic: first, governments have officially recognized the need for comprehensive and accurate community information delivered in ways compatible with the technologies emerging in our information society and, second, the proliferation of community networks across North America seems to be creating difficulties for I\& $R$ agencies in communi- 
ties where the roles of I\&R agencies and community networks are seen as indistinguishable. If community networks are, along with their other services, delivering the same services as I\&CR agencies, then can the roles of $I \& R$ agencies still be justified? Should they continue to be funded if community networks can perform the same service at a lower cost while providing users with greater access? Conversely, are community networks visible in areas already well served by $I \& R$ agencies? In answering these questions, we set out to establish whether or not the two types of information organizations were contributing in different ways to achieving efficient and effective delivery of community information. Is the shape and success of each of these two services in contributing to the community information process controlled in the same ways?

Figure 13 summarizes the foregoing analysis of each of two models of facilitator under each of the six facets of control. At this time, the two types of organizations are generally the same with respect to ownership and governance. However, as we pointed out, neither agency is bound to remain a not-for-profit, private-sector organization governed by a board of directors. Either could be set up in any of the other three quadrants. Which quadrant each occupies is a question of the private funders' intent in the private sector (fig. 6, quadrants $B$ and $D$ ) or government actively seeking control and placing either or both into either quadrant $A$ or $C$. There are some current differences in the sources of funding relied upon by the two types of agencies, with the older I\&R agencies enjoying a wider array of sources at present than the newer community networks. These differences may be short term, however, since both are actively seeking funding from all available sources. Neither has any legislated security in funding. Thus, on the first two facets of this analysis, there are currently no differences between these two. However, when you examine the final four facets of control over the information process (see fig. 13 again), these two types of organizations clearly play different roles in the information process. Moreover, analysis of these final four facets reveals characteristics of the two agencies that are inherent in their respective structures and thus less vulnerable to change than their respective current attributes under the first two facets.

That the I\&R agency is a node in the information cycle (fig. 9) is supported by the finding that it exercises complete control over three facets of the information process (access, ownership of information, and quality control) and partial control over the fourth (information flow). The I\&R agency is thus an active intermediary between direct service providers and the users. By contrast, the evidence that the community network is merely a conduit or channel (fig. 10) rather than a node is clear from the fact that it exercises control over only one facet: 


\begin{tabular}{|c|c|c|}
\hline FACET & $\begin{array}{l}\text { CONTROL IN } \\
\text { I \& R AGENCY }\end{array}$ & $\begin{array}{c}\text { CONTROL IN } \\
\text { COMMUNITY NETWORK }\end{array}$ \\
\hline $\begin{array}{l}\text { Organization } \\
\text { Ownership } \\
\& \\
\text { Governance }\end{array}$ & $\begin{array}{l}\text { Statutes governing the } \\
\text { Private, Not for Profit } \\
\text { Sector; Board of } \\
\text { Directors }\end{array}$ & $\begin{array}{l}\text { Statutes governing the } \\
\text { Private, Not for Profit } \\
\text { Sector; Board of } \\
\text { Directors }\end{array}$ \\
\hline $\begin{array}{l}\text { Sources } \\
\text { of } \\
\text { Funding }\end{array}$ & $\begin{array}{l}\text { Government, } \\
\text { Charities }\end{array}$ & $\begin{array}{l}\text { Charities, } \\
\text { (Government) }\end{array}$ \\
\hline $\begin{array}{l}\text { Information } \\
\text { Flow }\end{array}$ & $\begin{array}{l}\text { Shared by: } \\
\text {-service providers } \\
\text {-the I \& R agency } \\
\text {-users }\end{array}$ & $\begin{array}{l}\text { Principally shared by: } \\
\text {-service providers } \\
\text {-users }\end{array}$ \\
\hline Access & I \& R agency & $\begin{array}{l}\text { Technical: community } \\
\text { network; but beyond } \\
\text { technical: uncontrolled }\end{array}$ \\
\hline $\begin{array}{l}\text { Ownership } \\
\text { of } \\
\text { Information }\end{array}$ & $\begin{array}{l}\text { (in so far as applicable) } \\
\text { I \& R agency }\end{array}$ & $\begin{array}{l}\text { (in so far as applicable) } \\
\text { service providers }\end{array}$ \\
\hline $\begin{array}{l}\text { Quality } \\
\text { Control }\end{array}$ & I \& $R$ agency & $\begin{array}{l}\text { Primarily service } \\
\text { providers (some control } \\
\text { left with network) }\end{array}$ \\
\hline
\end{tabular}

Fig. 13.-Overview of facets and locations of controls 
access, and that only partially-in technical aspects. Indeed, the community network has been revealed as playing the role of a new, additional channel for dissemination and acquisition of information by others: between service providers and the public. It does not play an intermediary role. Indeed, it could provide a channel for the intermediaries themselves. An I\&R agency, for example, which is an intermediary could utilize a community network as one of its dissemination options. The possibility of this arrangement confirms the second hypothesis developed through the earlier analysis of community information definitions-there can be a direct relationship between the role of the I\&R agency and that of the community network. This actually could be an optimal arrangement for communities where both models exist. In this way, users would have twenty-four-hour access to the information from the I\&R agency, in combination with the network's other services, and the I\&R agency could ensure that the community continues to receive high-quality information. The responsibility that the $I \& R$ agency takes for its information could lead other service providers to prefer to feed their own information into the network via the I\&CR agency posting, rather than directly, in order to relieve themselves of the responsibility and effort required to maintain quality information about themselves. This possibility confirms the latter part of the second hypothesis of this inquiry.

\section{Conclusions and Further Suggestions}

Community networks have only been around since the late 1980 s and, though I\&R agencies have been serving the public in many different countries since the 1940 s, little research has been conducted on them. While agency and project reports in the professional literature are insightful and should be encouraged, more comparative, analytical, and empirical research is needed. For example, to date no research has been done that compares the quality of information from $I \& R$ agencies and community networks. Other research questions that need to be addressed are: (1) How does the public access community information? What are their chief access points, and do users consult different types of sources for different information needs? (2) What kinds of sources for community information do users find most helpful and how could they be improved? (3) What impact does electronic access to community information have on user help-seeking behavior? and (4) How does having an $I \& R$ agency provide community information through a community network affect the public's use of the I\&R agency and/ or the network? How do the resulting use patterns compare with those 
found in communities where the I\&\& agency and community network do not cooperate?

However, without awaiting or anticipating the results of this further work, this research has confirmed the fundamental point that I\&\&R agencies and community networks play different, though potentially complementary roles in the information process. Their fundamental compatibility is evident in their shared perspectives. Both desire to serve communities by empowering individuals, to help inform people so they can make better decisions and have a higher standard of living. This compatibility, coupled with this demonstrated distinctiveness, means that communities will be better served where agencies work with each other to optimally provide users with community information without sacrificing either access or quality. The I\&R agency can provide quality information in the restricted domain of information about a community that is useful to the community within the larger scope of the community network's efforts to provide all data that are flowing anywhere that is useful to a community.

\section{REFERENCES}

1. Manikowski, Dick. "Telecomputing Issues." Newsletter of the Alliance of Information and Referral Systems 18 (December 1993): 8-11.

2. Civille, Richard. A National Strategy for Civic Networking: A Vision of Change. Washington, D.C.: Center for Civic Networking, 1993.

3. Communications Canada. New Media . . New Choices. Ottawa: Communications Canada, 1992.

4. Gore, Al. "Remarks Prepared by Vice-President Al Gore, Royce Hall, UCLA." CCH Guide to Computer Law 60 (January 1994): 447.

5. Harris, Roma M., and Dewdney, Patricia. Barriers to Information: How Formal Help Systems Fail Battered Women. Westport, Conn.: Greenwood, 1994.

6. Geffert, Bryn. "Community Networks in Libraries: A Case Study of the Freenet P.A.T.H." Public Libraries 32 (April/May 1993): 91-99.

7. Avis, Andrew. "Public Spaces on the Information Highway: The Role of Community Network." M.A. thesis, University of Calgary, 1995. WWW Internet address: http://www.ucalgary.ca/UofC/faculties/GNST/theses/avis.

8. Beamish, Anne. "Communities On-Line: A Study of Community-Based Computer Networks." M.A. thesis, Massachusetts Institute of Technology 1995. WWW Internet address: http://alberti.mit.edu/arch/4.207/anneb/thesis/toc.html.

9. Cisler, Steve. "Building Electronic Greenbelts (version 1.1.1)." June 1993. Available through anonymous FTP at ftp.apple.com/alug/communet.

10. Heterick, Robert C. "The Blacksburg Electronic Village: A Field of Dreams." Technology and Libraries 12 (June 1993): 240-42.

11. Maciuszko, Kathleen. "A Quiet Revolution: Community Online Systems." ONLINE 14 (November 1990): 24-32.

12. Morino, Mario. "Assessment and Evolution of Community Networking." Paper presented 
at the Apple Conference on Building Community Computing Networks, Cupertino, Calif., May 4-6, 1994.

13. Nickerson, Gord. "Access to Global Contacts: Online Community Information Services." Campus-Wide Information Systems 10 (May/June 1993): 21-24.

14. Schuler, Doug. "Community Networks: Building a New Participatory Medium." Communications of the ACM 37 (June 1994): 39-51.

15. Toms, Elaine. "Free-Nets: Delivering Information to the Public." Public Libraries 33 (1994): 311-15.

16. Childers, Thomas. Information and Referral in Public Libraries. Norwood, N.J.: Ablex, 1984.

17. Manikowski, Dick, and Maas, Norman L., eds. "Comprehensive Bibliography of the Literature of Information and Referral." Information and Referral 14 (1992).

18. Levinson, Risha W. Information and Referral Networks: Doorways to Human Services. New York: Springer, 1988.

19. Wilkinson, Margaret Ann. "Impact of the Ontario Freedom of Information and Protection of Privacy Act, 1987 upon Affected Organizations." Ph.D. diss., University of Western Ontario, 1992.

20. Sales, Georgia. A Taxonomy of Human Services: A Conceptual Framework with Standardized Terminology and Definitions for the Field. 2d ed. Los Angeles: AIRS, 1991.

21. Information London. Agency Brochure. London, Ont.: Information London, 1993.

22. Alliance of Information and Referral Systems. Fact Sheet. Joliet, Ill.: Alliance of Information and Referral Systems, Inc., ca. 1994.

23. Information London. Community Services Directory. London, Ont.: Information London, 1994.

24. National Public Telecomputing Network. Community Comprting and the National Public Telecomputing Network. Cleveland, Ohio: National Public Telecomputing Network, ca. 1994.

25. Public Libraries Act, Revised Statutes of Ontario 1990, ch P. 44, as amended Statutes of Ontario 1993, ch 27, Schedule.

26. Statistics Canada. Policy Manual (Policy No. 3.6, approved November 12, 1992). Ottawa, Ont.: Statistics Canada, 1992.

27. Information London. Incorporation Documents and By-laws. London, Ont.: Information London, 1978.

28. Comporations Act. Revised Statutes of Ontario 1990, ch 38, as amended.

29. Charities Accounting Act. Revised Statutes of Ontario 1990, ch c. 10.

30. Charitable Gifts Act. Revised Statutes of Ontario 1990, ch c. 8.

31. National Capital Freenet. "About the National Capital Freenet." ca. 1994. WWW Internet address: http://www.ncf.carleton.ca/freeport/menu.main.

32. National Capital Freenet. "By-laws of the National Capital Freenet Incorporated." ca. 1994. WWW Internet address: http://www.ncf.carleton.ca/freeport/menu.main.

33. Alliance of Information and Referral Systems, Inc. (AIRS). AIRS Policy Paper: The Role of Information and Referral in the National Information Infrastructure. Joliet, Ill.: AIRS, October 1993.

34. Information London. Annual Report, 1993-1994. London, Ont.: Information London, 1994.

35. National Capital Freenet. "Financial Statements of National Capital Freenet Incorporated." Ca. 1994. WWW Internet address: http://www.ncf.carleton.ca/freeport/menu.main.

36. Alliance of Information and Referral Systems, Inc. National Standards for Information and Referral. Alexandria, Va.: United Way of America, 1991.

37. National Capital Freenet. "The Context of Public Access Community Networks." Ca. 1994. WWW Internet address: http://www.ncf.carleton.ca/freeport/menu.main. 


\section{COMMUNITY INFORMATION}

38. National Capital Freenet. "Account Information Statistics." ca. 1994. WWW Internet address: http://www.ncf.carleton.ca/freeport/menu.main.

39. Jensen, Dave. "Network Puts Providers in Data Fast Lane: Some Roadblocks Loom." Business Journal-Milwaukee 11 (December 1993): 12A-15A.

40. National Capital Freenet. "Priorities for Location of Public Access Terminals." 1993. WWW Internet address: http://www.ncf.carleton.ca/freeport/menu.main.

41. Walsh, Taylor. "Municipal Information Systems (Taylor Walsh Speech-transcript)." Computers in Libraries 12 (June 1992): 58-59.

42. Copyright Act. Revised Statutes of Canada 1985, c. c-42, as amended.

43. Wilkinson, Margaret Ann, and Kozak, Ellen. "A Comparison of U.S. and Canadian Copyright Law and the Effects of NAFTA." in Focus on the North American Intellectual Property: Proceedings of the American Bar Association Section on Intellectual Property Law. New Orleans: American Bar Association, 1994.

44. National Capital Freenet. "User Agreement." October 15, 1994. WWW Internet address: http://www.ncf.carleton.ca/freeport/menu main.

45. Woods, L. B., and Walker, Jon. "Automation of Community Information and Referral Services." Information Technology and Libraries 8 (December 1989): 393-99.

46. Gauthier, Michelle. "The Non-profit Association's Guide to the Freenet: A Model for Members and Public Relations." March 1992. WWW Internet address: http:// www.ncf.carleton.ca/freeport/menu.main.

47. Felsky, Martha. "The Legal Liability of Information Professionals." Canadian Journal of Information Science 14 (1989): 1-15.

48. Sookman, Barry. "The Liability of Information Providers in Negligence." Computer Law and Practice 5 (1989): 141-46. 